Ahora bien, la materialización de estos fondos digitalizados representa el acceso a once colecciones hemerográficas que en términos cuantitativos conforman un universo de cerca de 90 millones de páginas, de las cuales el equipo nacional aporta 9 millones que equivalen a 771 títulos de esta hemerografía, publicados en un lapso que va de 1840 a 1914. Escritos en diferentes idiomas, en su mayoría en español y una buena parte en inglés y francés, los fondos digitalizados en el país se encuentran bajo el resguardo y administración de la Hemeroteca Nacional Digital de México (HNDM). ${ }^{2}$ Estos registros incluyen materiales de libre acceso y de acceso restringido para su consulta dentro de las instalaciones de la Hemeroteca Nacional de México (HNM).

Proveedores de datos

Bavarian State Library

Berlin State Library

British Library

Cengage

Hamburg State and University Library

National Library of Finland

National Library of the Netherlands

Biblioteca Nacional de México

\section{Proceso e investigación}

La primera etapa de la puesta en marcha del proyecto OcEx se fundamentó en estudiar la digitalización de los fondos pertenecientes a la HNDM, lo que incluía conocer el tránsito de los fondos físicos hasta ser digitalizados, estudiar la base de datos, reflexionar e investigar qué criterios se tuvieron en cuenta en la

2 Este proyecto está financiado por Conacyt (FONCICYT 274861) a través de la convocatoria de Transatlantic Partnership for Social Sciences and Humanities 2016 Digging Into Data Challenge. organización-clasificación de los fondos y bases de datos, así como realizar entrevistas al personal involucrado en la creación de la HNDM. Es decir, el equipo destinó sus primeras actividades a entender cómo estaban conformadas las colecciones digitalizadas. Una parte de dichas indagaciones será publicada en un artículo titulado "El uso de periódicos digitalizados como fuente para trabajos de investigación". 3

La segunda etapa del proyecto concentró esfuerzos en trabajar la base de datos de la HNDM mediante el desarrollo de herramientas digitales y el estudio de casos.

\section{Herramientas digitales}

Cuando se habla de estudiar vastos depósitos de documentación como los millones de materiales hemerográficos que están comprendidos en un amplio lapso, es preciso señalar la importancia en el diseño y creación de herramientas digitales para tal fin. En consecuencia, el proyecto desarrolló herramientas basadas en el análisis del contenido lingüístico/temporal, las cuales estuvieron a cargo de Iván Vladimir Meza Ruiz y Marco Godínez. Se dividieron en dos tipos: por un lado, las herramientas de análisis basadas en el estudio y cuantificación del uso del lenguaje en las fuentes, que se realizó a través de "el paradigma denominado word2vec, usado en redes neuronales para identificar por palabra una representación vectorial a éste, al final cada palabra tiene un vector que lo representa". ${ }^{4}$ Así, cada término convertido en concepto arroja un entramado de palabras que permiten visualizar su entorno en un periodo determinado;

3 Isabel Galina Russell et al., "El uso de periódicos digitalizados como fuente para trabajos de investigación," será publicado en Revista Relaciones Estudios de Historia y Sociedad, Colegio de Michoacán (2020) http://www.revistarelaciones.com/index.php/ relaciones/index

4 Explicación de Iván Vladimir Meza Ruiz. 
un ejemplo de esto se puede visualizar aquí con el uso de los conceptos "Juárez" y "Maximiliano":

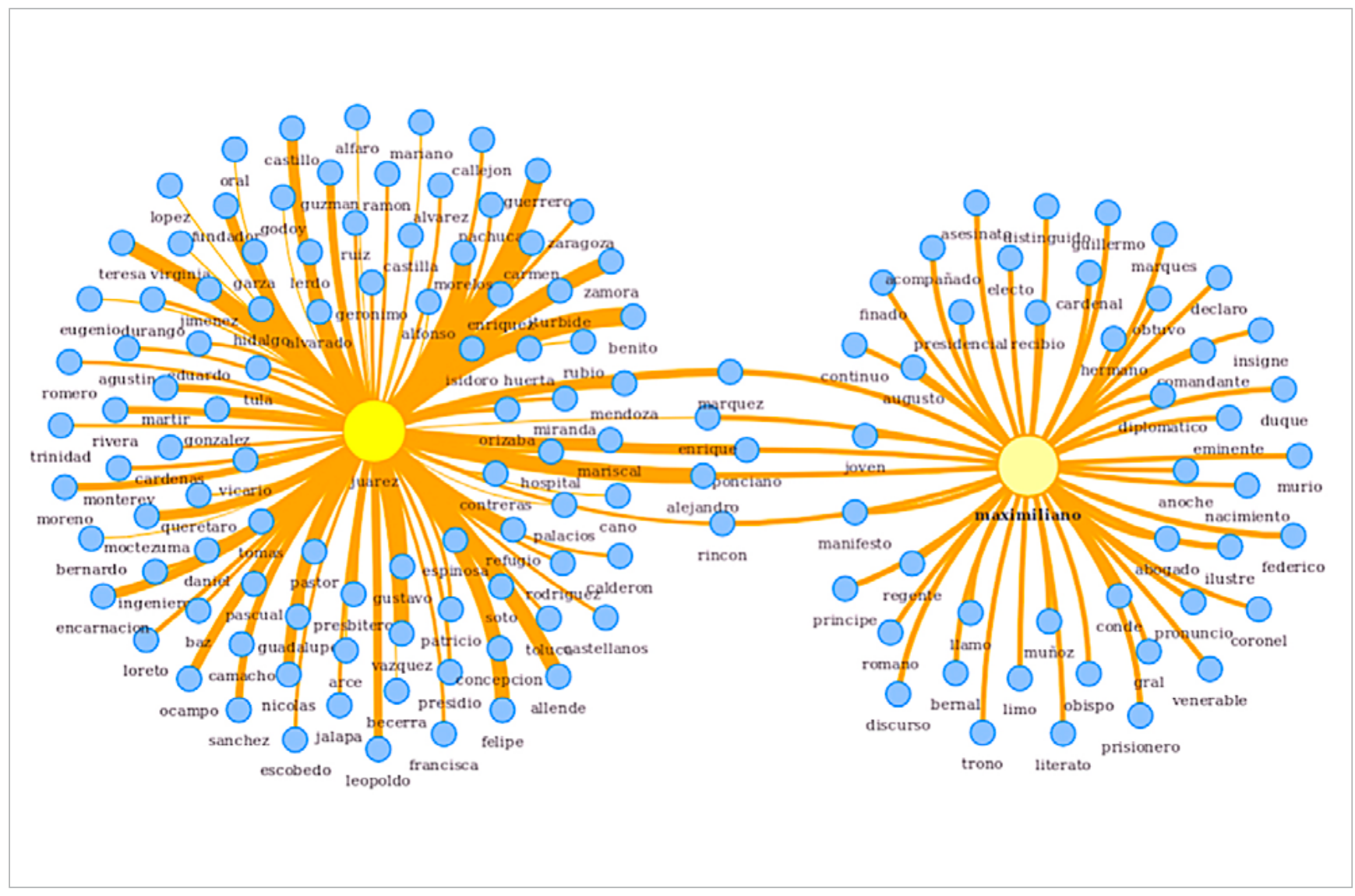

Elaboración: Intercambios Oceánicos.

Por otro lado está la elaboración de herramientas de visualización basada en node.js, pues admite una mayor interacción con la base de datos de la HNDM. Además de que permitió la extracción de datos estadísticos, también ayudó a visualizar fotografías, bajar archivos XML, representar vectores con el objeto de distinguir las palabras en sus relaciones, conceptos, generar imágenes basadas en un rango temporal amplio, entre otros alcances que se encuentran descritos en el sitio web del proyecto.

\section{Estudios de caso}

Ante la necesidad de diseñar una metodología dinámica que permitiera estudiar los flujos de información, ${ }^{5}$ se indagó en: saber cómo se difundían las noticias transcontinentalmente; si los periódicos profundizaban en el contenido una vez recibido el texto como noticia internacional y por cuáles vías lo hacían;

5 Intercambios Oceánicos entiende "flujo de información" como un término que tiene resonancias históricas: en el siglo XIX como un modo de referise a la forma en que los periódicos circulaban la información a través de una red internacional; en la actualidad, se entiende como la forma en que los investigadores buscan acceder a coleciones distribuidas de materiales digitales. 
investigar si estos flujos admitían la verificación del reúso de las noticias $\mathrm{y}$, de acuerdo con esto, qué variantes tenían los contenidos transmitidos. Por estas razones, el proyecto propuso a los grupos de investigadores postular siete noticias relevantes ocurridas entre 1840 y 1914, las cuales serían rastreadas en toda la base de datos ya conformada, temas cuyas conexiones conceptuales, históricas y literarias fueran posibles de enlazar en cada uno de los repositorios digitales a trabajar.

Este trabajo sería de relevancia para el estudio de la historia global de los siglos XIX y Xx; desde luego, el reto era enorme. Se trataba de trabajar en minería de datos, es decir, implicaba indagar en fuentes documentales de distintos formatos e idiomas, así como configurar herramientas para cada caso (entidades nombradas, palabras clave, análisis de sentimientos, entre otros) y superar las distancias físicas, académicas e institucionales. En este empeño, se acordó rastrear la noticia de siete eventos:

1. La erupción del Krakatoa en 1883.

2. El discurso ofrecido por el líder húngaro Lajos Kossuth en Washington en 1852.

3. El cable transatlántico.

4. La explosión del Maine y la guerra hispanoamericana.

5. La publicación del "Origen de las Especies".

6. La ejecución de Maximiliano en 1867.

7. El asesinato del gobernador general Bobrikov en 1904.

En consecuencia, una vez elegidos los temas se establecieron los parámetros para el rastreo y extracción de las noticias que finalmente formarían parte del corpus general: rango temporal de búsqueda (cada caso tendría uno sin importar el número de noticias a hallar); origen de la edición hemerográfica y de la noticia; fecha de emisión; vía o formato en que se emite la noticia (por ejemplo, si se había recibido por un cable transoceánico, telégrafo, teléfono, una editorial, un reportaje, entre otros medios); palabra usada en el buscador; texto de la noticia; idioma; nombre del repositorio digital donde se ubicaba; link correspondiente, e indicar, en caso de hallarse, si el registro contenía imágenes ilustradas.

Finalmente, una vez construido el corpus, se procedía al análisis basado en la lectura de cada una de las noticias. De esta manera se podía advertir, de acuerdo con la fuente documental, la naturaleza del registro, la repetición o replique que de este texto se hiciera en otros medios locales, la frecuencia del seguimiento realizado por la prensa de la época a la noticia en estudio, así como la vía de transmisión entre Europa y América. De esta etapa analítica se procedía a la cuantificación de los datos y al diseño de herramientas digitales para la diagramación de la información hallada en todos los repositorios hemerográficos utilizados. A continuación, el detalle de los tres casos donde el equipo México participó, y el resultado de la investigación:

\section{La explosión del Maine ${ }^{6}$}

La explosión del buque norteamericano en 1898 representó un importante suceso internacional dado su impacto en la prensa mundial. En el caso mexicano simbolizó un excepcional evento en el cual se demostraba el alcance y poderío de la nación vecina. Para el momento del hundimiento del Maine, la prensa mexicana estaba conformada por diarios que atendían comunidades enfrentadas en el marco de la guerra de independencia cubana en la confrontación

${ }^{6}$ El equipo México ha publicado un artículo resultado de esta investigación en: Rocío Castellanos et al., "'Si los telegramas no mienten'. Origen y circulación de las noticias de la Explosión del Maine en la prensa mexicana, febrero 1898," Revista de Historia de América 159 (Julio-diciembre 2020): 255-287. https:// revistasipgh.org/index.php/rehiam/article/view/644 Revisado el 13 de agosto, 2020. 
entre los Estados Unidos y España. Diarios en inglés y en español ofrecían un marco perfecto para el análisis de esta noticia. Como en los otros casos, el enfoque estuvo dirigido a indagar sobre el lugar de origen de las noticias, su tiempo de arribo, así como la narrativa del episodio en la prensa.

En la primera etapa de la investigación se rastrearon las notas publicadas en la prensa mexicana, norteamericana, alemana, británica y finlandesa. En el caso mexicano, las disponibles en la HNDM sobre la explosión del Maine que corresponden al corte temporal que va desde el 16 hasta el 23 de febrero de 1898.

Para esta búsqueda en la base de datos de la HNDM se usó la palabra "Maine", cuyos resultados se remiten solo a periódicos editados en Ciudad de México. Con anterioridad se intentó utilizar en el motor de búsqueda términos como "Explosion Maine" (sin acento), sin embargo, los resultados disminuían de forma considerable, por ello se decidió finalmente usar solo "Maine". Se obtuvo un total de 657 registros de 15 periódicos, de los cuales se extrajo de manera automatizada y utilizando un algoritmo para identificar expresiones, fecha y origen de la noticia. Luego se estudiaron contenidos y se hizo un reúso de telegramas, además se identificaron persona- jes y posiciones políticas tanto de voceros como de los diarios. Al sumar los hallazgos aportados por el equipo internacional, el corpus quedó compuesto por 2564 noticias.

El caso de la explosión del Maine atrajo la atención de los diarios mexicanos dadas las implicaciones políticas; estos periódicos insistieron en confrontar las distintas versiones, tanto las oficiales como las emitidas por los investigadores del caso. La fluidez de los telegramas se ve reflejada en las más de seiscientas noticias publicadas, entre las que se pueden distinguir, reportajes, artículos de opinión, gráficas e ilustraciones de la embarcación, así como textos literarios: poesía, canciones y rimas. Buena parte de dichos reportes escritos en inglés ocuparon las portadas de estos periódicos, cuya circulación era diaria. El diario El Correo Español junto a The Two Republics y The Mexican Herald fueron los más interesados en imprimir todos los telegramas remitidos desde distintos puntos en el mundo (tanto los recibidos en las horas de la mañana como los últimos telegramas de la tarde, los cuales llegaban vía Galveston y por el cable procedente de Londres).

En términos metodológicos, utilizamos herramientas digitales como identificación de expresiones

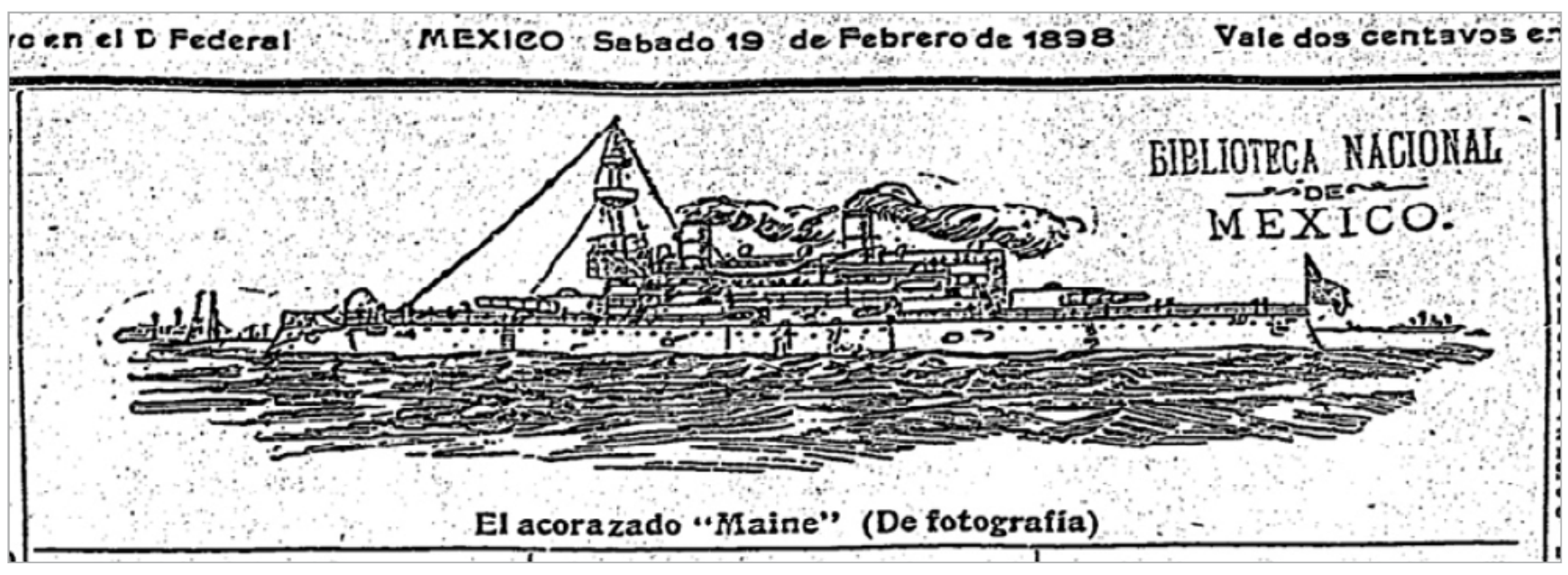

"El Maine", El Imparcial. Diario Ilustrado de la Mañana (México) 19 de febrero de 1898: 1.

https://bit.ly/30YeNRs (02-08-2019). 
regulares: KeyWords y NER, con el fin de identificar patrones de circulación y temas relevantes en los diarios; asimismo, usamos el método de nubes de palabras y el de frecuencia de entidades nombradas. Los resultados indican un predominio notable de las noticias producidas en Estados Unidos y un dominio de la narrativa sobre el acontecimiento a partir de la información generada por instituciones norteamericanas, incluso en la prensa española en la Ciudad de México.

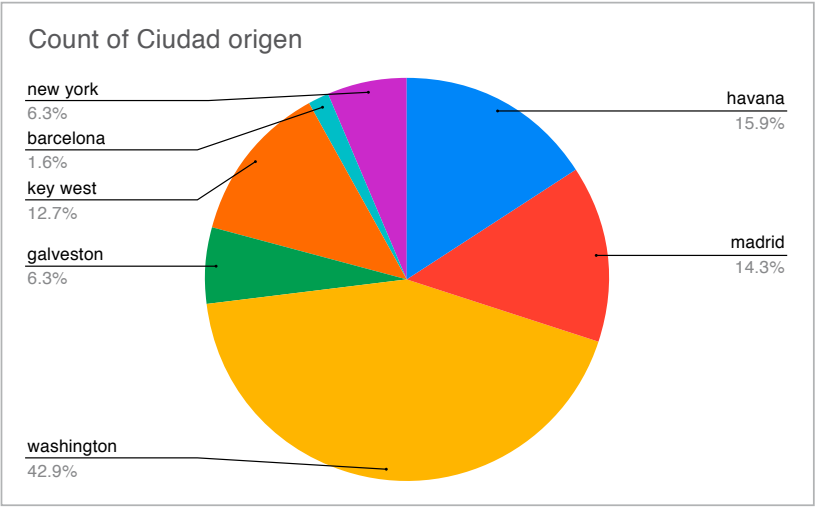

Elaboración: Intercambios Oceánicos. Origen de las noticias publicadas en el periódico mexicano The Two Republics, consultado de 17-02-1898 a 22-02-1898.

\section{La ejecución de Maximiliano ${ }^{7}$}

Como se ha visto a lo largo de la utilización de las bases de datos, los resultados han arrojado distintos escenarios. El caso de Maximiliano es también particular pues, aunque la ejecución del archiduque se llevó a cabo en Querétaro el 19 de junio de 1867, la noticia se filtró en la prensa nacional hasta julio del

7 La publicación de un artículo sobre este caso de estudio se encuentra en dictamen, saldrá bajo el título "Transnational News Flows on the Execution of Emperor Maximilian of Mexico in 1867: A methodological experiment in the study of digitized newspaper corpora", bajo la autoría de Adán Lerma Mayer, Ximena Gutierrez-Vasques, Ernesto Priani Saisó y Hannu Salmi. mismo año. Es decir, a pesar de ser un evento de gran trascendencia local con importantes implicaciones políticas internacionales, el gobierno de Benito Juárez comunicó la muerte de Maximiliano unas semanas después. Fue así como la propagación de dicha noticia en el exterior se cumplió casi treinta días después, esto obligó a establecer el lapso para la revisión de materiales hemerográficos del 5 al 20 de julio de 1867.

Dadas las particularidades de las 1511 noticias localizadas con la palabra "Maximiliano" que muestran los apasionados reclamos de la prensa internacional, así como las tensiones regionales por el rápido juicio y ejecución impuesta a quien fuera el emperador de México, el equipo de investigadores que se ha ocupado de este caso decidió implementar una metodología novedosa y experimental a las noticias. De esta manera, a las mismas se aplicó el análisis de sentimientos a través del estudio de los contenidos en el corpus de registros multilingüe que contiene notas de periódicos publicados en cinco países: Austria, Finlandia, Alemania, México y Estados Unidos.

El fusilamiento de Maximiliano rápidamente polarizó la prensa internacional, la controversia radicaba en dos posturas identificadas en dos grupos: los que apoyaban la decisión del gobierno liderado por Juárez y los que condenaban la osadía de haber condenado a muerte a un miembro de la realeza europea. En concordancia con esto, los ejes de análisis para la metodología se centraron en: identificar estas diferencias en las más de 1500 noticias mediante el análisis automatizado de sentimientos; indagar su flujo por los canales globales de transmisión (agencias noticiosas, cables transatlánticos y telegramas); y establecer las posturas de cada medio internacional para identificar los sesgos políticos en el replique de las noticias. De este modo, por ejemplo, se logró detectar la tendencia sentimental de algunos medios: la prensa austriaca/alemana tenía un notable sesgo negativo "bárbaro" de la noticia en contraposición a los medios mexicanos, los cuales hacían notar una imagen de neutral a positiva del hecho. 


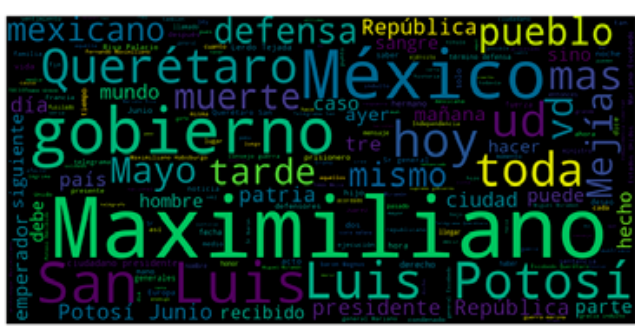

Nube de palabras de periódicos mexicanos.

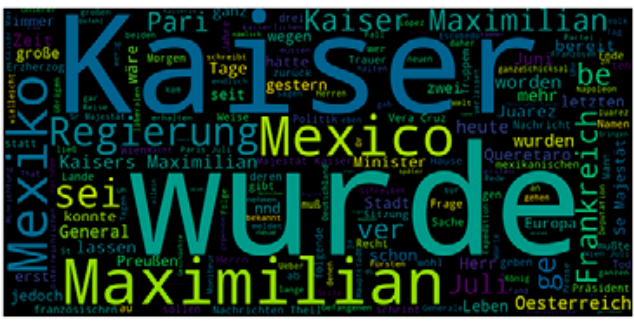

Nube de palabras de periódicos austriacos.

\section{El asesinato del gobernador general Bobrikoff ${ }^{8}$}

Nikolai Bobrikov fue asesinado en la ciudad de Helsinki la noche del 16 de junio de 1904, ejercía como gobernador general de Finlandia, cargo que ocupaba desde 1898. Su asesino, Eugen Schauman, hijo de un senador, se suicidó en el lugar de los hechos. Dicha noticia política se propagó con una asombrosa rapidez; tanto, que en México el día 17 ya se habían publicado los primeros telegramas; lo mismo sucedió con los diarios alemanes, norteamericanos, entre muchos otros. El efecto dominó sucedió gracias a la red de agencias de noticias. La primera en transmitir el suceso fue la agencia finlandesa Kelsinki, seguida de la red de canales oficiales ubicados en San Petersburgo. Éstas se conectaban con el entramado mundial de transmisión de información vía cables transoceánicos y redes telegráficas.

8 El resultado de esta investigación se publicó bajo el título: Mila Oiva et al., "Spreanding News in 1904: The Media Coverage of Nikolay Bobrikov's Shooting," Media History (2019): 1-17. https://doi.org/10.1080/13688 804.2019.1652090 Revisado el 28 de julio de 2020.
Para abordar la exploración documental en los periódicos de Australia, Austria, Dinamarca, Finlandia, Francia, Alemania, Suecia, Países Bajos, Estados Unidos y México, a los que se sumaron los diarios publicados por la prensa rusa ubicados en la colección de microfilm de la Biblioteca Nacional de Finlandia, se estableció el lapso de búsqueda entre el 17 y el 24 de junio de 1904; es decir, una semana siguiente a la muerte del general. La palabra por usar en el buscador sería Bobrikov, sin embargo, en la HNDM no arrojaba resultados, por tanto, se usaron términos como Bobrikoff, Finland y Finlandia.

El corpus se completó con un total de 1475 registros sobre el acontecimiento; el primer medio mexicano en informar fue de habla inglesa, el The Mexican Herald:

St. Petersburg, June 16, 6:16 p.m.- General Bobrikoff, governor general of Finland, was shot and mortally wounded at 11 o'clock this morning at the entrance to the Finnish senate at Helsingfors. The assassin, a man named Schaumman, a son of Senator Schaumman. Immediately committed suicide. Brobrikoff was shot in the stomach and neck. He is in a dying condition. The attack is believed to be due to Finnish patriotism... ${ }^{9}$

La investigadora Laura Martínez Domínguez, encargada del caso y coautora del artículo, detectó que la prensa de habla hispana dio poco o nada de cobertura a la noticia y que la agencia usada para transcribir los telegramas fue Associated Press, con base en Estados Unidos. De acuerdo con el análisis aplicado al total de noticias, se pudo detectar el origen de las referencias y sus circuitos de tránsito mundial; pero quizá lo más importante, dado el aporte científico, es haber podido detectar el reúso de los contenidos

9 "General Bobrikoff, Governor General of Finland, shot by son of senator," The Mexican Herald (Ciudad de México), 17 de junio de 1904: 1. https://bit.ly/3ffwWiM Revisado el 9 de mayo de 2018. 


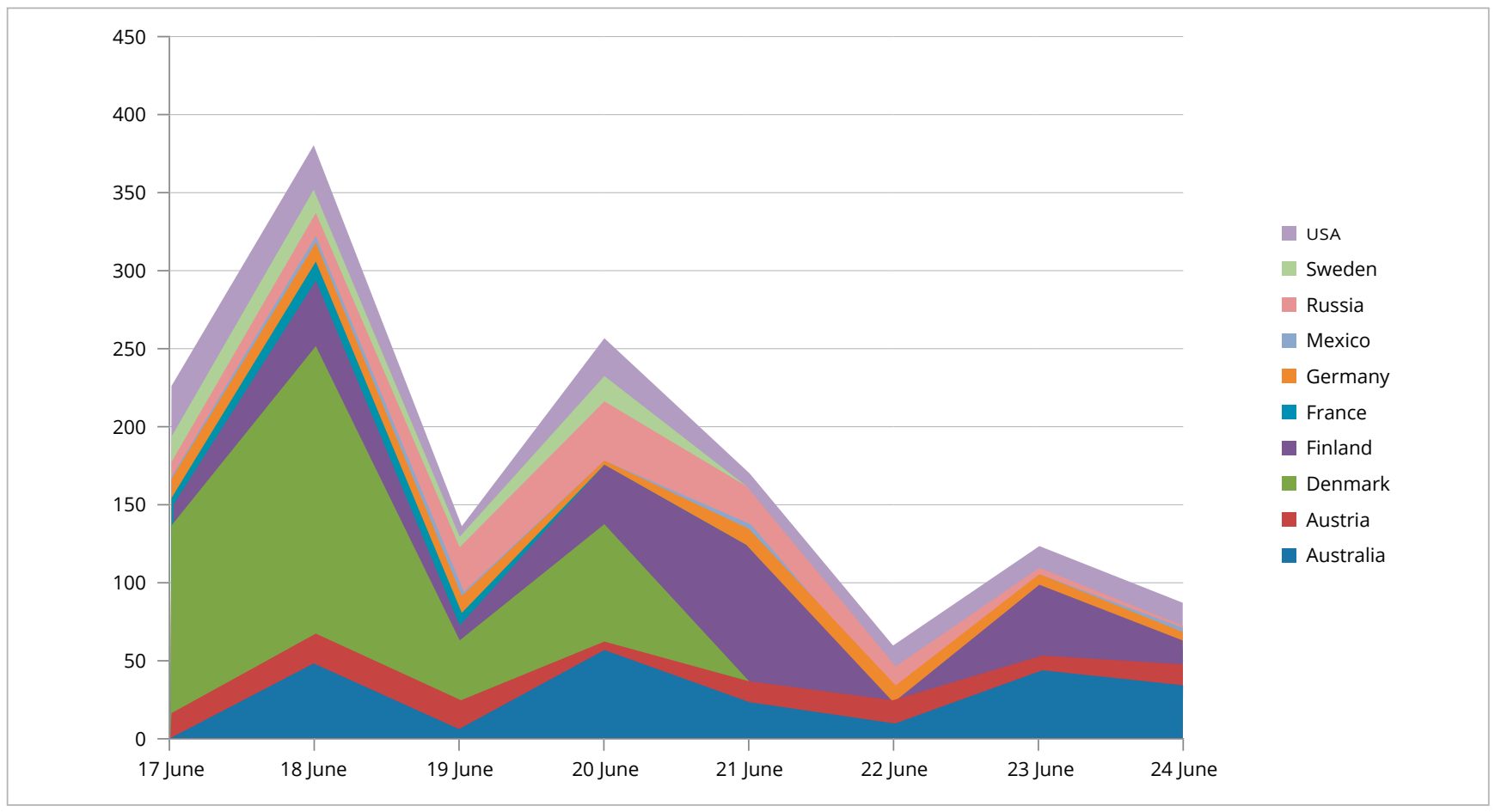

Ciudades de origen e intensidad de la noticia sobre el asesinato del general Bobrikov.

Imagen: Hannu Salmi.

y la similitud de los textos. Aunque para lograrlo sólo fueron útiles los datos obtenidos de Australia, Austria, Finlandia, Alemania, Estados Unidos y México debido a que en estos corpus se pudo obtener el total de caracteres contenidos en la noticia, así como los metadatos. $^{10}$

\section{Otras actividades}

Es importante señalar que, a lo largo de estos dos años de trabajo en equipo y correspondencia con investigadores de otros países, surgieron múltiples actividades. Los integrantes del equipo mexicano participaron en numerosos eventos para dar a conocer el proyecto y, quizá lo más importante, mostrar cómo se puede hacer historia desde las humanidades digitales, gracias a los valiosos repositorios

10 Mila Oiva et al. Spreading News in 1904, Media History (2019): 4. https://bit.ly/2PbafRZ Revisado el 28 de julio, 2020. documentales existentes en México, en especial el de la HNDM. Se llevaron a cabo entrevistas al personal de la hemeroteca y se impartieron tres talleres abiertos al público en sus instalaciones: el primero fue una sesión informativa con el objetivo de presentar el proyecto y crear una red de colaboradores interesados en las humanidades digitales; el segundo, titulado "Introducción a herramientas para el análisis de acervos digitalizados", coordinado por el equipo y con dos invitados especiales y, el tercero, "De bibliografía a cartografía: la producción de mapas digitales a partir de bibliografías", impartido por el doctor Alex Gil, de la Universidad de Columbia.

\section{A modo de conclusiones}

Experimentar con la minería de datos en los casos mencionados, elegidos para que estuviesen distribuidos a lo largo de todo el periodo comprendido en el proyecto general 1840-1914, permitió no sólo construir corpus y artículos académicos, sino conocer 
visualmente la historia y desarrollo de la prensa en el mundo. Resultó fascinante entender la evolución de la prensa escrita y cómo se imponían con el tiempo algunas prácticas que se instituían como características (por ejemplo, cuando se imprimía a dos columnas, luego a cuatro, más tarde a seis, pero ya con la aparición de ilustraciones hechas a partir de fotografías); rastrear noticias para conocer los flujos de información y para entender cómo se recibían los telegramas; entender el papel de las agencias de noticias que surgieron rápidamente como producto de la globalización para controlar el circuito de la información; saber si se transcribían los textos dado el costo de cada palabra para el periódico receptor, así como aprender sobre las abreviaturas utilizadas por esta misma razón. OcEx es, sin duda, un gran paso en este universo de las investigaciones basadas en materiales hemerográficos; sin embargo, ahora con el respaldo de las humanidades digitales se abre un portal de millones de posibilidades para los jóvenes humanistas y para todos los investigadores en general.

Mas allá de dar especificaciones técnicas, que bien se pueden hallar en las publicaciones particulares del proyecto o en su sitio web, interesa enfatizar en la magnífica oportunidad para profundizar en las herramientas digitales mencionadas. De ellas se pueden generar circuitos de noticias para el siglo XIX y $\mathrm{xx}$, identificar la importancia de los contenidos generados en formato de noticia para exponer un evento específico de la historia o el contexto histórico de cada caso.

Poder identificar el uso y reúso de una noticia abrirá nuevos universos de investigación y, en consecuencia, de aportes científicos que, a su vez, otorguen la posibilidad de estudiar conceptos en bases de datos para, por ejemplo, crear un marco conceptual en una tesis fundada en un proyecto con implicaciones mundiales cuya metodología esté basada en la comparación.

Por supuesto, se afrontan problemas metodológicos y aunque no se ahondará en ello, sí es reconocible la existencia de inconvenientes para trabajar con el reconocimiento óptico de caracteres (OCR, por sus siglas en inglés) de una base de datos como la de la HNDM, pues, finalmente, transcribir noticias es un método más preciso para obtener mejores resultados, como se constató en cada uno de los casos de estudio antes relatados. Aunque ya se dieron pasos, queda claro que es un reto por superar; por ello se debe insistir en la mejora de la calidad del ocr.

Para finalizar, en lo personal, quiero manifestar un enorme agradecimiento a la HNDM y al equipo por haberme permitido formar parte de un grupo científico interdisciplinario como Intercambios Oceánicos.

Fuentes manuscritas

Hemeroteca Nacional de México, México (HNM)

Fondo Hemeroteca Nacional Digital de México (HNDM)

El Imparcial. Diario Ilustrado de la Mañana (Ciudad de México)

The Mexican Herald (Ciudad de México)

The Two Republics (Ciudad de México)

Referencias

Castellanos Rueda, Rocío, Ernesto Priani Saisó, y Laura Martínez Domínguez. "'Si los telegramas no mienten'. Origen y circulación de las noticias de la Explosión del Maine en la prensa mexicana, febrero 1898, " Revista de Historia de América no. 159 (2020): 255-287. https:// revistasipgh.org/index.php/rehiam/article/view/644

Galina Russell, Isabel, Ernesto Priani Saisó, Miriam Peña Pimentel, Rocío Castellanos Rueda, y Laura Martínez Domínguez. "El uso de periódicos digitalizados como fuente para trabajos de investigación." Revista Estudios de Historia y Sociedad, Colegio de Michoacán (2020). http://www.revistarelaciones.com/index.php/ relaciones/index [Pendiente de publicación]

Intercambios Oceánicos. Trazando redes de información global en repositorios de periódicos históricos, 1840-1914. https://intercambiosoceanicos.iib.unam. $\underline{\mathrm{mx} / \text { index.html }}$

Oiva, Mila, Asko Nivala, Hannu Salmi, Otto Latva, Marja Jalava, Jana Keck, Laura Martínez Domínguez, and James Parker. "Spreading News in 1904." Media History (2019). https://doi.org/10.1080/13688804.2019.1652090 